\title{
EVALUATION OF THE SINGH INDEX FOR MEASURING OSTEOPOROSIS
}

\author{
V. C. M. KOOT, S. M. M. J. KESSELAER, G. J. CLEVERS, \\ P. DE HOOGE, T. WEITS, CHR. VAN DER WERKEN \\ From the Diakonessenhuis and University Hospital, Utrecht, The Netherlands
}

$\mathbf{W}$ e studied the reliability of the Singh classification of trabecular bone structure in the proximal femur as a measure of osteoporosis, using kappa statistics. Radiographs of fractures of the femoral neck or trochanteric region in 80 consecutive patients were assessed by six observers. The interobserver variation was large; only three of 72 radiographs were given the same classification by all six observers and the kappa values ranged from 0.15 to 0.54 . The intraobserver variation showed substantial strength of agreement; kappa values ranged from 0.63 to 0.88 .

In 77 patients dual-energy $\mathrm{X}$-ray absorptiometry was used to measure bone mineral density. The results were compared with those of the Singh classification: we found no correlation.

J Bone Joint Surg [Br] 1996;78-B:831-4.

Received 27 December 1995; Accepted after revision 6 February 1996

In elderly patients with proximal femoral fractures the degree of osteoporosis may help to determine the choice of treatment. The Singh index is commonly used to assess osteoporosis (Singh, Nagrath and Maini 1970), and is based on the radiological appearance of the trabecular bone structure of the proximal femur on a plain anteroposterior radiograph. Dual-energy X-ray absorptiometry (DEXA) provides a more precise estimate of bone mineral density (Kawashima and Uhthoff 1991; Lang et al 1991; Prince et

V. C. M. Koot, MD

S. M. M. J. Kesselaer, MD

G. J. Clevers, MD, PhD

Department of Surgery

P. de Hooge, MD, PhD

Department of Nuclear Medicine

T. Weits, MD, $\mathrm{PhD}$

Department of Radiology

Diakonessehuis, Bosboomstraat 1, 3582 KE Ultrecht, The Netherlands.

Chr. van der Werken, MD, PhD, Professor of Surgery

PO Box 85500, 3508 GA Utrecht, The Netherlands.

Correspondence should be sent to Dr V. C. M. Koot at Secr. Heelkunde Huispostnummer GO4. 228, Academisch Ziekenhuis, Heidelberglaan 100, 3584 CX Utrecht, The Netherlands.

(C)1996 British Editorial Society of Bone and Joint Surgery 0301-620X/96/51218 \$2.00 al 1993) and is considered to be the 'gold standard' for measuring osteoporosis (Sartoris 1994). We assessed the interobserver and intraobserver agreement of readings of the Singh index and compared the indices for measuring osteoporosis (Sartoris 1994) with the results of DEXA.

\section{PATIENTS AND METHODS}

We reviewed 80 consecutive patients over 55 years of age admitted to our hospital in 1994 with a fracture of the femoral neck or trochanteric region. Preoperative radiographs of each patient, with the identification labels covered, were assessed to determine the Singh index by six observers. These were one consultant radiologist (A), two trauma surgeons (B and C), one general surgeon (D), one surgeon in training $(\mathrm{E})$ and one junior house officer $(\mathrm{F})$, and each studied the series of radiographs independently. They were asked to apply the Singh index by comparing the trabecular bone pattern in the proximal femur with the reference scale published by Singh et al (1970). This has a six-point scale from grade VI, in which all the major trabecular systems are visible, to grade I in which only the primary compressive trabeculae can be seen (Fig. 1). We compared the results of the six observers to determine interobserver agreement.

One week later, ten of the previously scored radiographs were presented again to each of the six observers in a new and random order for reassessment of the Singh index. The first and second results by each observer were compared to determine intraobserver agreement. The reliability of the Singh index was expressed in terms of interobserver and intraobserver agreement in pairs using weighted Cohen's kappa statistics. The kappa value can vary from -1 (complete disagreement) through 0 (chance agreement) to +1 (complete agreement).

In the first week after operative treatment of the hip fracture, 77 of the 80 patients had DEXA, using a Norland XR 36 scanner (Norland, USA) (radiation dose 5 to 10 mrem), which was programmed to measure and calculate the bone mineral density (BMD, $\mathrm{g} / \mathrm{cm}^{2}$ ) of the femoral neck, Ward's triangle and the trochanteric region (Fig. 2). All patients were positioned in the same way.

We compared the BMD with the results of the Singh classification, using the results of the observer with the highest intraobserver agreement (trauma surgeon C). Finally, we performed analysis of variance on the data to 

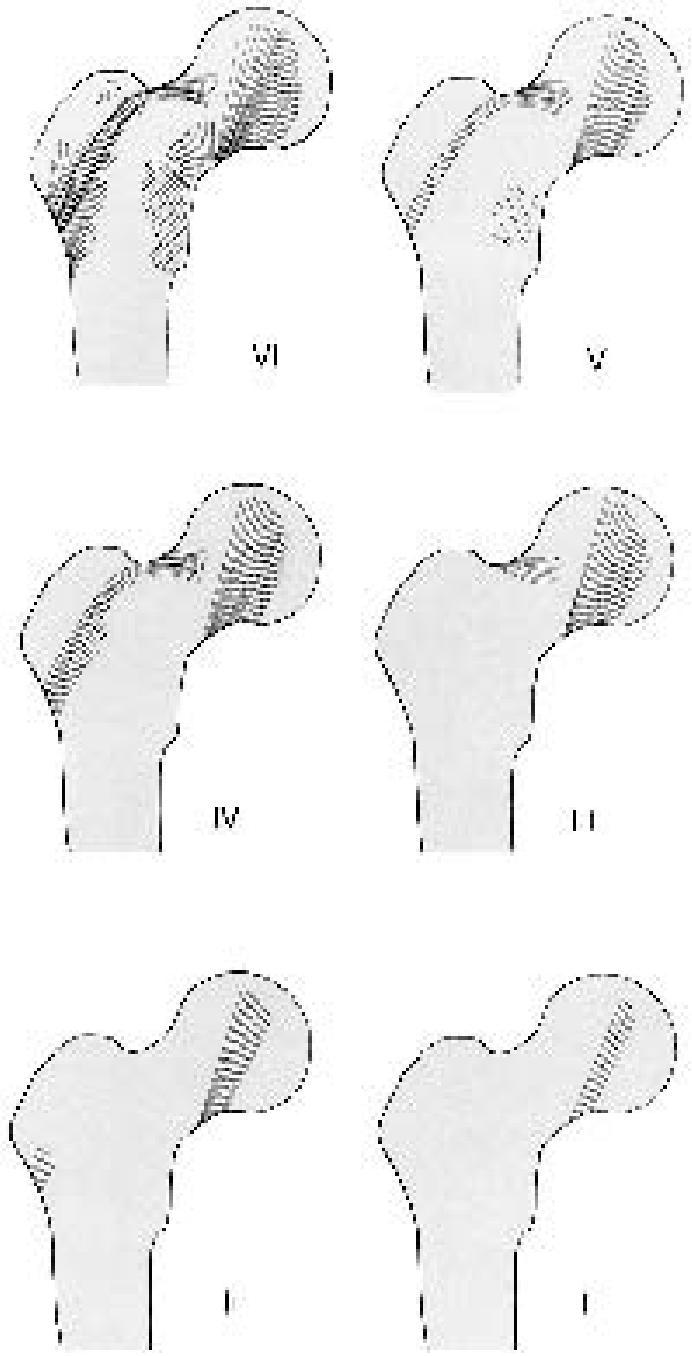

Fig. 1

Diagram to show the basic trabecular patterns of the Singh index, from grade VI (normal) to grade I (severe osteoporosis).

calculate the percentage of variance (multiple $\mathrm{R}^{2} \times 100 \%$ ) of BMD which was 'explained by' the Singh grade.

\section{RESULTS}

Eight radiographs were excluded from the study because of their poor technical quality. Only three of the remaining 72 fractures were classified identically by all observers $(4 \%)$. Eight were classified by five of the six observers (11\%), but the fact that the abberant eight classifications were made by different observers must be taken into account. The kappa values for interobserver agreement ranged from 0.15 to 0.54 (mean 0.33). Intraobserver agreement was reached in 37 of 60 radiographs $(62 \%)$. The kappa values for intraobserver agreement ranged from 0.63 to 0.88 (mean 0.78) (Table I). The best agreement scenarios from Table I are shown in detail in Figures 3 and 4. Table II shows the results after collapsing the six categories into three. After

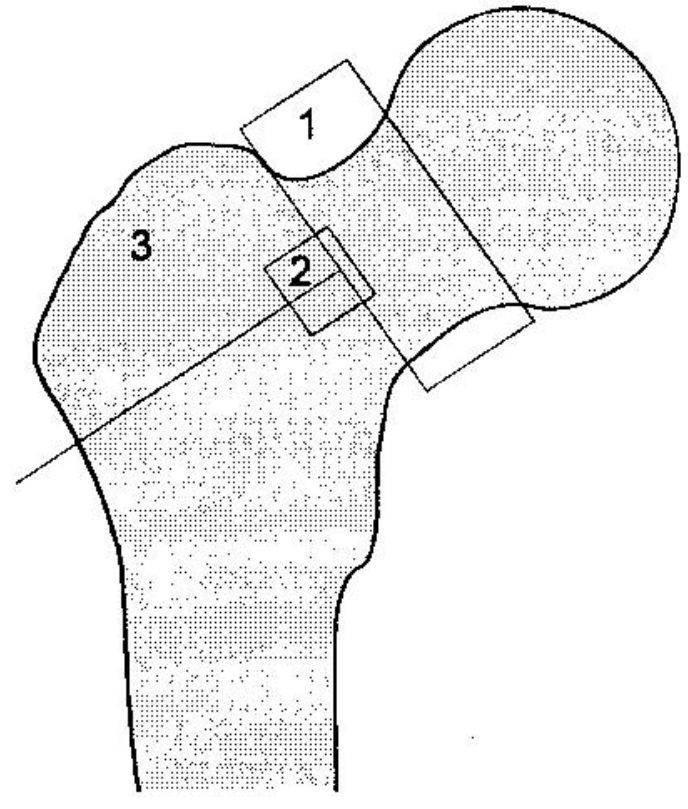

Fig. 2

Preprogrammed areas of interest for measurement of bone mineral density by dual-energy $\mathrm{X}$-ray absorptiometry $(1=$ neck, $2=$ Ward's triangle, $3=$ trochanteric region).

\begin{tabular}{|c|c|c|c|c|c|c|}
\hline & $I$ & II & III & IV & $\mathrm{V}$ & VI \\
\hline I & 3 & 1 & 1 & & & \\
\hline II & 1 & 18 & 6 & & & \\
\hline III & & 11 & 11 & 1 & & \\
\hline IV & & 5 & 5 & 3 & & \\
\hline $\mathrm{V}$ & & 1 & & 5 & & \\
\hline VI & & & & & & \\
\hline
\end{tabular}

Fig. 3

Interobserver agreement between the observers $\mathrm{C}$ and $\mathrm{F}$. The Singh grades are shown as I to VI in the vertical and horizontal axes.

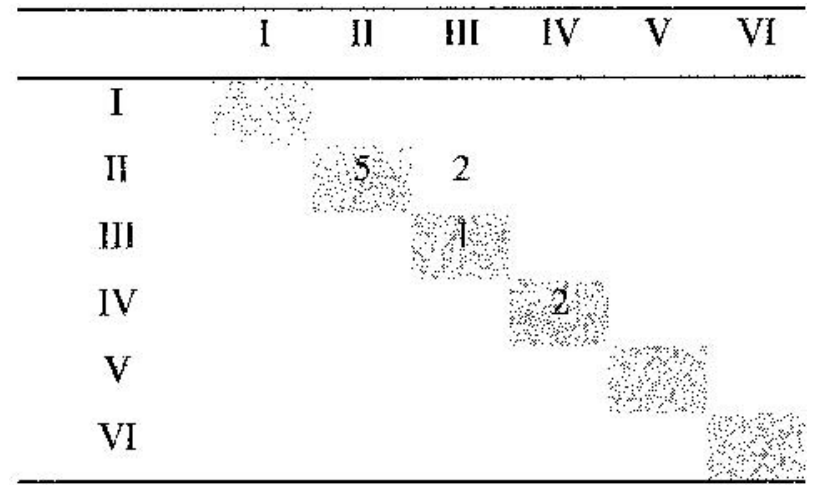

Fig. 4

Intraobserver agreement for the best observer (C). The Singh grades are shown as I to VI in the vertical and horizontal axes. 


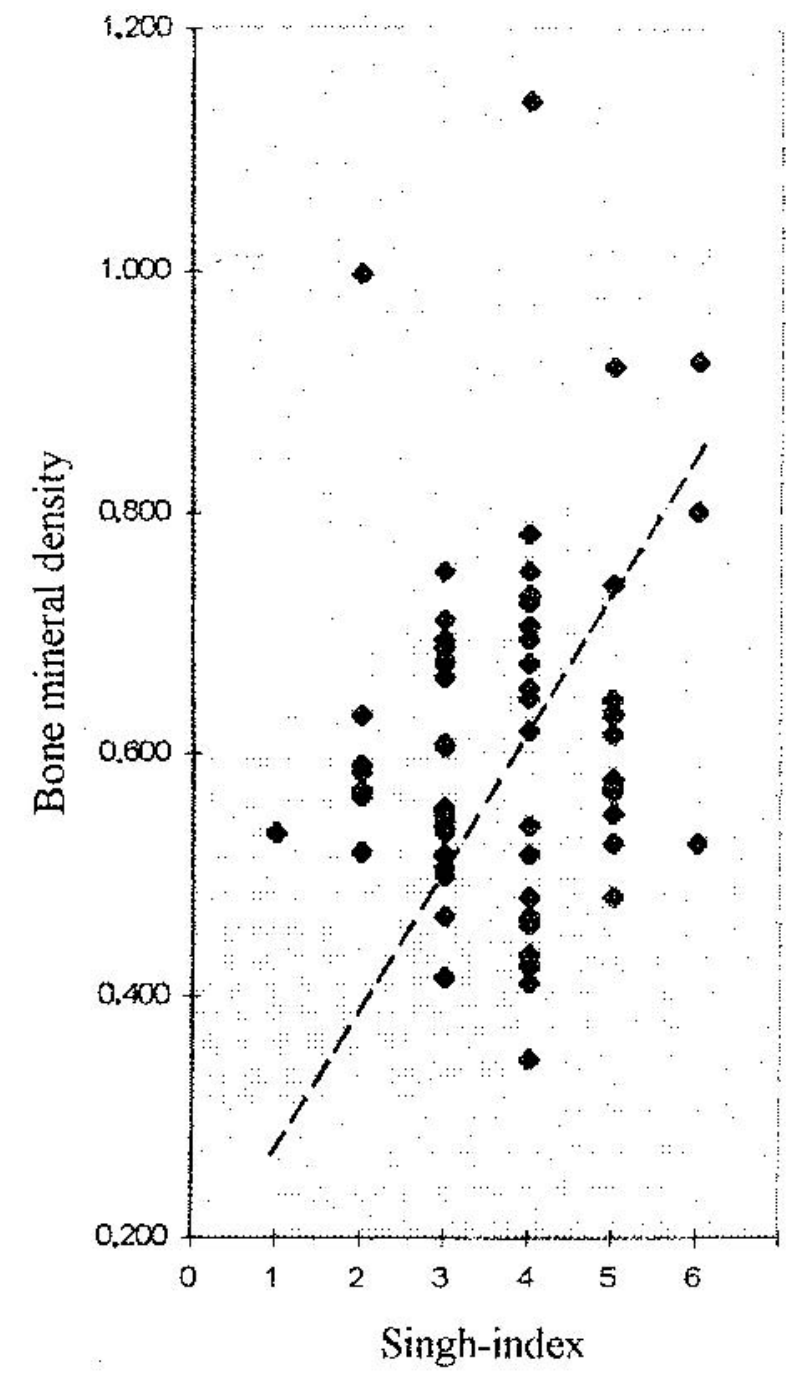

Fig. 5

Scatter diagram showing the lack of relationship between the Singh index and bone mineral density (the hatched line gives the expected relationship (Kawashima and Uhthoff 1991)).

this simplification the kappa values for interobserver agreement ranged from 0.01 to 0.54 and those for intraobserver agreement from -0.11 to +0.82 .

The BMD measured by DEXA ranged from $0.35 \mathrm{~g} / \mathrm{cm}^{2}$ to $1.14 \mathrm{~g} / \mathrm{cm}^{2}$. We found absolutely no correlation between the Singh index and BMD (Fig. 5). The percentage of variance 'explained' by the Singh index was $6.5 \%$.

\section{DISCUSSION}

Diagnostic classifications are useful if they help decisions about treatment or if they have a prognostic value. The Singh index is a diagnostic classification and is probably the most widely used method of estimating the degree of osteoporosis in daily practice and in clinical and research papers. We have tried to establish its accuracy by assessing the reproducibility and by comparing it with the BMD.
Table I. Weighted kappa values for the interobserver and intraobserver agreement using a six-point Singh scale

\begin{tabular}{lll}
\hline & Kappa value & \\
\cline { 3 - 3 } Observers & Interobserver $(\mathbf{n}=\mathbf{7 2})$ & Intraobserver $(\mathbf{n}=\mathbf{1 0})$ \\
\hline $\mathrm{A}$ & & 0.63 \\
$\mathrm{AB}$ & 0.54 & \\
$\mathrm{AC}$ & 0.16 & \\
$\mathrm{AD}$ & 0.08 & \\
$\mathrm{AE}$ & 0.26 & 0.73 \\
$\mathrm{AF}$ & 0.14 & \\
$\mathrm{~B}$ & & \\
$\mathrm{BC}$ & 0.20 & \\
$\mathrm{BD}$ & 0.15 & 0.88 \\
$\mathrm{BE}$ & 0.40 & \\
$\mathrm{BF}$ & 0.25 & \\
$\mathrm{C}$ & & \\
$\mathrm{CD}$ & 0.53 & 0.85 \\
$\mathrm{CE}$ & 0.42 & \\
$\mathrm{CF}$ & 0.54 & 0.81 \\
$\mathrm{D}$ & & \\
$\mathrm{DE}$ & 0.36 & 0.74 \\
$\mathrm{DF}$ & 0.46 & \\
$\mathrm{E}$ & & \\
$\mathrm{EF}$ & 0.42 & \\
F & & \\
\hline
\end{tabular}

Table II. Weighted kappa values of interobserver and intraobserver agreement (using the three-point scale)

\begin{tabular}{lll}
\hline & Kappa value & \\
\cline { 3 - 3 } Observers & Interobserver $(\mathbf{n}=\mathbf{7 2})$ & Intraobserver $(\mathbf{n}=\mathbf{1 0})$ \\
\hline $\mathrm{A}$ & & -0.11 \\
$\mathrm{AB}$ & 0.38 & \\
$\mathrm{AC}$ & 0.01 & \\
$\mathrm{AD}$ & 0.05 & \\
$\mathrm{AE}$ & 0.13 & 0.74 \\
$\mathrm{AF}$ & 0.06 & \\
$\mathrm{~B}$ & & \\
$\mathrm{BC}$ & 0.18 & \\
$\mathrm{BD}$ & 0.09 & 0.82 \\
$\mathrm{BE}$ & 0.29 & \\
$\mathrm{BF}$ & 0.19 & \\
$\mathrm{C}$ & & \\
$\mathrm{CD}$ & 0.35 & 0.60 \\
$\mathrm{CE}$ & 0.40 & \\
$\mathrm{CF}$ & 0.54 & 0.78 \\
$\mathrm{D}$ & & \\
$\mathrm{DE}$ & 0.34 & 0.70 \\
$\mathrm{DF}$ & 0.31 & \\
E & & \\
$\mathrm{EF}$ & 0.39 & \\
F & & \\
\hline
\end{tabular}

Interobserver agreement showed an unacceptable level of kappa values ( 0.15 to 0.54$)$, but the intraobserver agreement had substantial strength (kappa values 0.63 to 0.88). Landis and Koch (1977) suggested that a kappa value of 0.6 distinguished between moderate and substantial strength of agreement. Intraobserver agreement, however, is generally less important than interobserver agreement, since different observers apply the Singh index in a different way.

We found no generally acceptable level of kappa value as a coefficient of agreement. Because we had shown a poor ability to differentiate between six closely related grades, we rearranged the results into three grades: 1 and 2 as A, 3 
and 4 as $\mathrm{B}$, and 5 and 6 as $\mathrm{C}$, hoping that this would reduce both the interobserver and intraobserver variation. The results were disappointing for both interobserver agreement (kappa values 0.01 to 0.54 ) and for intraobserver agreement (kappa values -0.11 to 0.82 ). They showed even less agreement after the regrouping of the Singh index. Both for six grades and three grades we found no correlation between the Singh index and bone densitometry.

Conclusion. On the basis of our findings we consider that the Singh index has no value in assessing the grade of osteoporosis.

No benefits in any form have been received or will be received from a commercial party related directly or indirectly to the subject of this article.

\section{REFERENCES}

Kawashima T, Uhthoff HK. Pattern of bone loss of the proximal femur: a radiologic, densitometric and histomorphometric study. J Orthop Res 1991;9:634-40.

Landis JR, Koch GG. The measurement of observer agreement for categorical data. Biometrics 1977;33:159-74.

Lang P, Steiger P, Faulkner K, Gluer C, Genant HK. Osteoporosis: current technics and recent developments in quantitative bone densitometry. Radiol Clin North Am 1991;29:49-76.

Prince RL, Geelhoed E, Harris T, et al. Screening for osteoporosis by bone densitometry: a stratified intervention approach. Osteoporosis Int 1993;3:Suppl 1:75-7.

Sartoris DJ. Clinical value of bone densitometry. Am J Roentgenol 1994;163:133-5.

Singh M, Nagrath AR, Maini PS. Changes in trabecular pattern of the upper end of the femur as an index of osteoporosis. J Bone Joint Surg [Am] 1970;52-A:457-67. 